\title{
EFFECTS OF STRETCHING EXERCISES WITH OR WITHOUT BACLOFEN ON SPASTICITY, FLUID INTAKE AND CALORIES INTAKE IN \\ CEREBRAL PALSY CHILDREN
}

1. HOD Physical Therapy. Department of Physical Therapy. Idrees Teaching Hospital Sialkot Pakistan. 2. Consultant Rehabilitation Specialist/CEO. Islamabad Physical Therapy \& Rehabilitation Centre Islamabad. Pakistan

3. Lecturer. Faculty of rehabilitation \& Allied Health Sciences, Riphah International University. Islamabad Pakistan.

4. Assistant Professor Isra Institute of Rehabilitation Sciences. Isra University Islamabad Pakistan

5. Assistant Professor Faculty of rehabilitation \& Allied Health Sciences, Riphah International University. Islamabad Pakistan

Correspondence
Muhammad Ahmed
HOD Physical Therapy. Department of Physical Therapy.

Correspondence
Muhammad Ahmed
HOD Physical Therapy. Department of Physical Therapy. Idrees Teaching Hospital Sialkot Pakistan.

E-mail: physiopkahmad@gmail.com

Received on: 21-08-2001 Revision on: 03-04-2021

Published on: 30-06-2021

Citation; Ahmed M, Liaqat A, Kanwal N, Irshad A,

Waqqar S. Effects of stretching exercises with or

without baclofen on spasticity, fluid intake and calories

intake in cerebral palsy children. T Rehabili. I.

$$
\text { 2021:05(01);203-207 }
$$

soi: $21-2017 /$ re-trimol05iss01p203

doi: https://doi.org/10.52567/tri.v5i01.59
Muhammad Ahmed ${ }^{1}$ : Conception, data collection, writing: Revised and accountable for all aspects

Aleem Liaqat ${ }^{2}$ : Conception, Revised and accountable for all aspects

Nabeela Kanwal ${ }^{3}$ : Analysis \& interpretation of data, Revised and accountable for all aspects

Asma Irshad ${ }^{4}$ Interpretation of data, Revised and accountable for all aspects

Saira Waqqar ${ }^{5}$ : Analysis \& interpretation of data, Revised and accountable for all aspects

\section{ABSTRACT}

Objectives: to find out the effectiveness of stretching exercises and baclofen alone and combined in spastic cerebral palsy children on spasticity, fluid and calorie intake. Material \& Methods: A single-blinded, randomized control trial was conducted at Allama Iqbal Hospital, and Idrees Teaching Hospital. The $\mathrm{n}=60$ participants between $5-12$ years, having spasticity score of 2 or more on Modified Ashworth Scale (MAS). The participants were randomly divided into three treatment groups receiving Baclofen, sustained stretching exercises and combination baclofen and sustained stretching exercises. Data were collected at baseline and after six weeks as fluid and calorie intake, and spasticity on Modified Ashworth Scale (MAS). Results: The result showed significant difference $(p<0.05)$ among group with large effect size while comparing mean differences of Fluid intake $\left\{F(d f)=2,57(988.603), \eta^{2}=0.972\right.$, $p<0.001\}$ and Calories intake $\left\{F(d f)=2,57(166.877), \eta^{2}=0.854, p<0.001\right\}$. While there was no significant difference in mean difference of spasticity $\{F(d f)=2,57(2.119), p=0.130\}$. Conclusion: baclofen along with stretching exercises significantly improved fluid, calorie intake and spasticity

Keywords: Calories, cerebral palsy, spasticity, stretching exercises

\section{INTRODUCTION}

Cerebral Palsy is a group of permanent disorders of development of movement and posture, causing activity limitation, that are attributed to nonprogressive disturbances that occurred in the developing fetal and infant. The motor impairments of CP is often followed by disturbances of perception, cognition, behaviour, communication, epilepsy, sensation, and musculoskeletal problems. ${ }^{1}$ The worldwide prevalence of CP is 2.5 per 1000 , but it may differ from 1-6 per 1000 births. As every 2 to 3 children out of 1000 have CP, which makes it the most common neurodevelopmental motor disability in children. $^{2}$

The most common type of $\mathrm{CP}$ is spastic which comprises $80 \%$ of total cases reported. ${ }^{3}$ The upper motor neuron lesion causes spasticity, hyperreflexia, and extensor plantar response. Also, spastic cerebral palsy patients have mass, slow and effortful movements instead of fine movements. ${ }^{4}$ Spastic CP patient usually presents with muscle imbalance, stand with bent knees and legs tightly closed together i.e. scissors-type gait. The patient usually has typical pattern of muscle weakness, sensory and motor control impairment, ${ }^{1}$ which affects the activities of daily living of children. ${ }^{5}$ In spastic CP patient malnutrition and growth failure is common condition and mainly occurs due to reduced fluid and calorie intake, excessive loss of nutrients and abnormal energy metabolism. ${ }^{6}$

The management of $\mathrm{CP}$ requires multidisciplinary team approach to address medical, psychological, social, intellectual, and educational issues to gain functional independence and improves performance in activities of daily living. In many previous studies different treatment approaches such as pharmacological, non-pharmacological and surgical were being used for the management of CP patient. ${ }^{4}$ Physical therapy, occupational therapy and electrical stimulation is an integral part of $\mathrm{CP}$ management, ${ }^{7}$ however oral anti-spasticity drugs such as benzodiazepines, baclofen, and tizanidine are also used to reduce general spasticity. 8,9

A previous literature showed significant improvement in spasticity after stretching exercises in spastic cerebral palsy children. ${ }^{10}$ Also, intrathecal baclofen is also effective in reducing spasticity by acting on receptors in brain and spinal cord to reduce abnormal tone. ${ }^{11,12}$ However studies have been conducted previously but as far as authors' knowledge based on literature review, no published data was found on effectiveness of baclofen along with stretching exercise on fluid, calorie intake and spasticity. The aim of the study was to find out the effectiveness of stretching 
exercises and baclofen alone and combined in spastic cerebral palsy children on spasticity, fluid and calorie intake.

\section{METHODOLOGY}

A single-blinded, randomized control trial was conducted at Allama Iqbal Hospital, and Idrees Teaching Hospital, Sailkot having good patient turn over and timely follow up of patients over a time period of six months. The study was initiated after taking approval from authorities. Informed consent was obtained from all patients which was in accordance to the deceleration of Helsinki.

The participants with the age group of 5-12 years, and who had a score of 2 or more on Modified
Ashworth Scale (MAS) were included in the study, While participants were excluded who had other type of CP with additional systemic comorbidities were excluded. Initially, $\mathrm{n}=196$ patients were evaluated for the eligibility and $n=136$ were excluded. Therefore, $n=60$ patients fulfilled the inclusion criteria and showed willingness to participate in the study, were randomly divided into Baclofen, Sustained stretching exercises and combination of Baclofen and sustained stretching exercises group (Figure 1). The patients were recruited through non-probability consecutive sampling technique. The simple random sampling through toss \& trial method was used for allocation of participants into three groups.

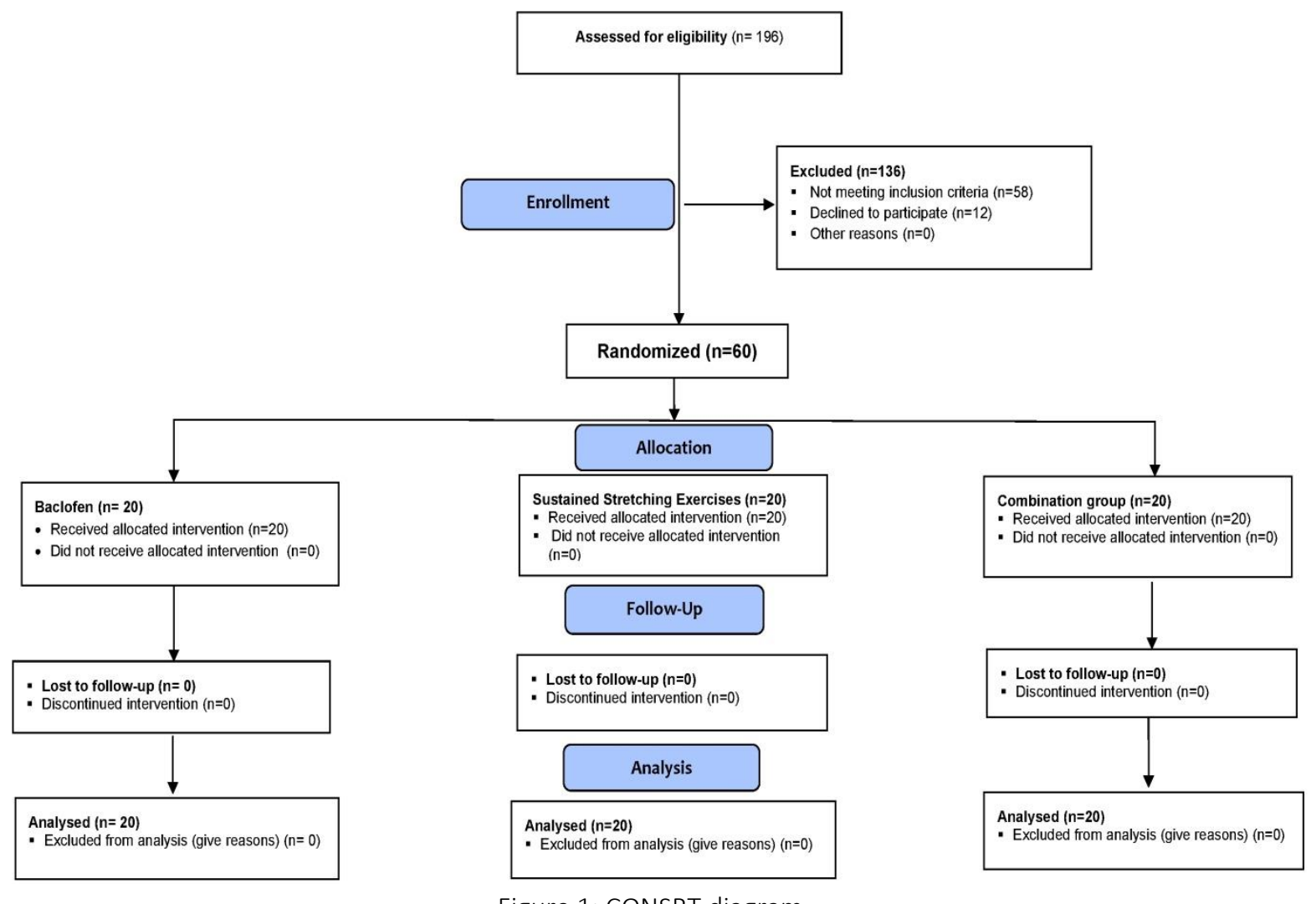

Figure 1: CONSRT diagram

The baclofen group received $5 \mathrm{mg}$ of baclofen each six to eight hourly. The maximum dosage was increased until the point when side effects occurred. The successful dosage ranged from 15 mg to $160 \mathrm{mg}$ for every day or more. Baclofen was presented over a multi week titration period and after that kept up at the most astounding endured dosage for three weeks. The treatment stage was isolated by a multi week tranquilize withdrawal and a fourteen day washout period. The baclofen was administered by a clinician.
In sustained stretching exercises group stretching of upper and lower limb major muscle groups was carried by asking the patient to hold for 30 seconds, rest, and repeat 3-5 times. Stretching was done on alternate days, one session per day, for six weeks. The third group received combination of baclofen and sustained stretching with same dosage as given to both groups individual. The participants of each group were followed up for 6 weeks. 
Data were collected by Performa / Questionnaire, which calculated basic demographics, BMI, fluid and calorie intake, and Modified Ashworth Scale (MAS). MAS was used to measure spasticity. ${ }^{13}$ The One Way ANOVA was applied on mean difference (MD) of pre-post score after six week's intervention. Statistical significance was set at $p<0.05$ and eta square $\left(\eta^{2)}\right.$ was used for effect size. SPSS Version 21 was used to analyze the data.

\section{RESULTS}

The mean age of the study participants was $10.57 \pm 2.902$ year. Regarding gender distribution $\mathrm{n}=33$ were females and $\mathrm{n}=27$ were males participated in the study. Of the total participants, $n=18$ had normal weight, $n=9$ were obese and the remaining $n=33$ were overweight.

The result showed significant difference $(p<0.05)$ among group with large effect size while comparing mean differences of Fluid intake $\left\{F(d f)=2,57(988.603), \quad \eta^{2}=0.972, \quad p<0.001\right\}$ and
Calories intake $\left\{F(d f)=2,57(166.877), \eta^{2}=0.854\right.$, $p<0.001\}$. While there was no significant difference in mean difference of spasticity $\{F(d f)=2,57(2.119)$, $\mathrm{p}=0.130$,$\} .$

The post hoc analysis showed that the fluid intake were significantly improved in group receiving stretching and baclofen both as compared to baclofen alone (MD=357, $d=2.18,95 \% \quad C l=-$ 381.8159 to -332.1841$)$ and stretching alone ( $M D=317, d=1.94,95 \% C l=291.8039$ to 342.1961). The calories intake also showed significant improvement same as fluid intake in group receiving stretching and baclofen both as compared to baclofen alone $(M D=180.75, d=2.13$, 95\% Cl=-205.7496 to -155.7504$)$ and stretching alone (MD=140.50, $d=1.66,95 \% \mathrm{Cl}=115.5004$ to 165.4996). While comparing the groups regarding spasticity, no statistical significant difference $(p \geq 0.05)$ was observed among the groups as shown in table 1.

Table 1: between Group Analysis

\begin{tabular}{|c|c|c|c|c|c|c|c|c|c|}
\hline & \multicolumn{2}{|c|}{ Baclofen } & \multicolumn{2}{|c|}{ Stretching } & \multicolumn{2}{|c|}{$\begin{array}{l}\text { Stretching With } \\
\text { Baclofen }\end{array}$} & \multirow[t]{2}{*}{$F(d f)$} & \multirow[t]{2}{*}{ Sig } & \multirow[t]{2}{*}{$\eta^{2}$} \\
\hline & Mean & SD & Mean & SD & Mean & SD & & & \\
\hline Fluid Intake (ml) & -306.5 & 16.23 & -346.5 & 18.43 & -663.5 & 41.45 & $988.60(2,57)$ & .000 & .97 \\
\hline Calories Intake (kcal) & -327 & 32.78 & -367.25 & 22.91 & -507.75 & 40.47 & $166.87(2,57)$ & .000 & .85 \\
\hline Spasticity (MAS) & 0.35 & 0.48 & -0.4 & 0.50 & 0.65 & 0.48 & $2.119(2,57)$ & .130 & .069 \\
\hline
\end{tabular}

Significance level: $<0.05^{*},<0.01^{* *} \&<0.001^{* * *}$

\section{DISCUSSION}

The aim of the study was to determine the effectiveness of baclofen and stretching exercises on fluid and calorie intake, and spasticity in spastic cerebral palsy children. According to the results of the current study, combination of baclofen and stretching exercises significantly improved fluid, calorie intake after 6 weeks of intervention.

The results of this study is also in coherence with the previous literature in which intrathecal baclofen (ITB) improved the weight gain and nutritional status i.e. fluid and caloric intake in spastic/hypertonic CP children. And improved nutritional status leads to good overall general health and decreases the risk of infections, illness and mortality rate in spastic CP population. ${ }^{14}$ Furthermore, spasticity measured on MAS was also improved in all groups, supports by the previous study; in which baclofen reduce spasticity in upper and lower limb by acting at the level of spinal cord to obstruct the neurotransmitters that cause spasticity. $^{15}$

A previous study by Kraus $T$ et al in which It had been found that intrathecal baclofen not only decreased spasticity but also improved quality of life and satisfaction level of parents and children. ${ }^{16}$ The spasm and pain relief, ease of care, improved sleep and independence of patients were also clinically improved after intrathecal baclofen. ${ }^{17}$ It might be a reason of improved fluid and calorie intake, because loss of appetite compromised oral and general health are consequences of pain. ${ }^{18}$

Moreover, the results of recent study showed significant improvement in spasticity, fluid and calorie intake after 6 weeks of stretching exercises of both upper and lower limb which also relates with the previous findings. ${ }^{19}$ In previous literature it has been discussed that increased spasticity leads to poor nutrition i.e. fluid and calorie 
intake. ${ }^{20}$ Slow and continuous stretching exercises are effective for reducing spasticity and it reduced spasticity might be a reason of improved nutritional status. ${ }^{21}$ The possible reasons of decreased fluid and calorie intake are constipation, oral motor disorders, gastroesophageal reflux, ${ }^{22}$ physical factors i.e. immobility and psychosocial factors i.e. pain, social isolation and depression. ${ }^{23}$ It has been discussed in previous study that decrease lower extremity and trunk movement leads to constipation, however, stretching exercises of upper and lower extremity significantly reduce constipation in spastic $\mathrm{CP}$, which may contribute to improve fluid and calorie intake. ${ }^{24}$ Also, stretching exercises reduces the risk of contractures and improve mobility and flexibility to some extent and therefore improves performance in activities of daily living. ${ }^{25,26}$

Additionally, the results of the study showed more significant improvement in group receiving both therapies, baclofen and stretching exercises. As per authors' knowledge, so far no study has been published to determine the effectiveness of baclofen along with stretching exercises on fluid, calorie intake and spasticity in spastic cerebral palsy children.

\section{CONCLUSION}

It has been concluded that baclofen and stretching exercises alone significantly improved fluid, calorie intake and spasticity. However, baclofen along with stretching exercises showed more significant improvement.

\section{REFERENCES}

1. Yasser Awaad, Tamer Rizk and Emira Švraka . Management of Spasticity and Cerebral Palsy, Cerebral Palsy - Challenges for the Future, Emira Svraka, IntechOpen,2014. DOI: 10.5772/58311. Available from: https://www.intechopen.com/chapters/46305 (Accessed on 18th March 2021)

2. Bangash AS, Hanafi MZ, Idrees R, Zehra N. Risk factors and types of cerebral palsy. J Pak Med Assoc. 2014;64(1):103-7. PMID: 24605730.

3. Wasiak J, Hoare B, Wallen M. Botulinum toxin A as an adjunct to treatment in the management of the upper limb in children with spastic cerebral palsy. Cochrane Database Syst Rev. 2004;(3):CD003469. doi: 10.1002/14651858.CD003469.pub2. PMID: 15266487.

4. Krigger KW. Cerebral palsy: an overview. Am Fam Physician. 2006:1;73(1):91-100. PMID: 16417071.

5. Rostami HR, Arastoo AA, Nejad SJ, Mahany MK, Malamiri RA, Goharpey S. Effects of modified constraint-induced movement therapy in virtual environment on upper-limb function in children with spastic hemiparetic cerebral palsy: a randomised controlled trial. NeuroRehabilitation. 2012;31(4):357-65. doi: 10.3233/NRE-2012-00804. PMID: 23232158..

6. Nutrition in neurologically impaired children. Paediatr Child Health. 2009;14(6):395-401. PMID: 20592978; PMCID: PMC2735385.

7. Novak I, Mclntyre S, Morgan C, Campbell L, Dark L, Morton $\mathrm{N}$, Stumbles E, Wilson SA, Goldsmith S. A systematic review of interventions for children with cerebral palsy: state of the evidence. Dev Med Child Neurol. 2013;55(10):885-910. doi: 10.1111/dmcn.12246. Epub 2013 Aug 21. PMID: 23962350.

8. Shamsoddini A, Amirsalari S, Hollisaz MT, Rahimnia A, Khatibi-Aghda A. Management of spasticity in children with cerebral palsy. Iran J Pediatr. 2014;24(4):345-51. Epub 2014. PMID: 25755853; PMCID: PMC4339555.

9. Tickner N, Apps JR, Keady S, Sutcliffe AG. An overview of drug therapies used in the treatment of dystonia and spasticity in children. Arch Dis Child Educ Pract Ed. 2012;97(6):230-5. doi: 10.1136/archdischild-2011-301170. Epub 2012 15. PMID: 22896738.

10. Elshafey MA, Abd-Elaziem A, Gouda RE. Functional stretching exercise submitted for spastic diplegic children: a randomized control study. Rehabil Res Pract. 2014;2014:814279. doi: 10.1155/2014/814279. Epub 2014 . Erratum in: Rehabil Res Pract. 2016;2016:1615024. PMID: 25143834; PMCID: PMC4131100..

11. Hasnat MJ, Rice JE. Intrathecal baclofen for treating spasticity in children with cerebral palsy. Cochrane Database Syst Rev. 201513;(11):CD004552. doi: 10.1002/14651858.CD004552.pub2. PMID: 26563961.

12. Hoving MA, van Raak EP, Spincemaille GH, Palmans $L$, Sleypen FA, Vles JS; Dutch Study Group on Child Spasticity. Intrathecal baclofen in children with spastic cerebral palsy: a double-blind, randomized, placebo-controlled, dose-finding study. Dev Med Child Neurol. 2007;49(9):654-9. doi: 10.1111/j.1469-8749.2007.00654.x. PMID: 17718820..

13. Charalambous CP. Interrater reliability of a modified Ashworth scale of muscle spasticity. Classic papers in orthopaedics: Springer; 2014: 415-7.

14. McCoy AA, Fox MA, Schaubel DE, Ayyangar RN. Weight gain in children with hypertonia of cerebral origin receiving intrathecal baclofen therapy. Arch Phys Med Rehabil. 2006;87(11):1503-8. doi: 10.1016/j.apmr.2006.07.270. PMID: 17084127.

15. Albright AL. Baclofen in the treatment of cerebral palsy. J Child Neurol. 1996;11(2):77-83. doi: 10.1177/088307389601100202. PMID: 8881981.

16. Kraus T, Gegenleitner K, Svehlik M, Novak M, Steinwender $G$, Singer $G$. Long-term therapy with intrathecal baclofen improves quality of life in children with severe spastic cerebral palsy. Eur J Paediatr Neurol. 2017;21(3):565-569. doi: 10.1016/j.ejpn.2017.01.016. Epub 2017 Feb 11. PMID: 28237420.

17. Krigger KW. Cerebral palsy: an overview. Am Fam Physician. 2006;73(1):91-100. PMID: 16417071..

18. Pells JJ, Presnell KE, Edwards CL, Wood M, Harrison MO, DeCastro L, et al. Moderate chronic pain, weight and dietary intake in African-American adult patients with sickle cell disease. J Natl Med Assoc. 2005;97(12):1622-9. PMID: 16396054; PMCID: PMC2640739..

19. Tupimai T, Peungsuwan P, Prasertnoo J, Yamauchi J. Effect of combining passive muscle stretching and whole body vibration on spasticity and physical performance of children and adolescents with cerebral palsy. J Phys Ther Sci. 2016;28(1):7-13. doi: 10.1589/jpts.28.7. Epub 2016 Jan 30. PMID: 26957720; PMCID: PMC4755966.

20. Ghai A, Garg N, Hooda S, Gupta T. Spasticity - Pathogenesis, prevention and treatment strategies. Saudi J Anaesth. 2013;7(4):453-60. doi: 10.4103/1658-354X.121087. PMID: 24348300; PMCID: PMC3858699. 
21. Shamsoddini A, Amirsalari S, Hollisaz MT, Rahimnia A, Khatibi-Aghda A. Management of spasticity in children with cerebral palsy. Iran J Pediatr. 2014;24(4):345-51. Epub 2014 May 9. PMID: 25755853; PMCID: PMC4339555.

22. Penagini F, Mameli C, Fabiano V, Brunetti D, Dilillo D, Zuccotti GV. Dietary Intakes and Nutritional Issues in Neurologically Impaired Children. Nutrients. 2015;7(11):9400-15. doi: 10.3390/nu7115469. PMID: 26580646; PMCID: PMC4663597.

23. Karim T, Jahan I, Dossetor R, Giang NTH, Van Anh NT, Dung $\mathrm{TQ}$, Nutritional Status of Children with Cerebral PalsyFindings from Prospective Hospital-Based Surveillance in Vietnam Indicate a Need for Action. Nutrients. 2019;11(9):2132. doi: 10.3390/nu11092132. PMID: 31500109; PMCID: PMC6769778.

24. Awan WA, Masood T. Role Of Stretching Exercises In The Management Of Constipation In Spastic Cerebral Palsy. J Ayub Med Coll Abbottabad. 201;28(4):798-801. PMID: 28586619..

25. Trajano GS, Nosaka K, Blazevich AJ. Neurophysiological Mechanisms Underpinning Stretch-Induced Force Loss. Sports Med. 2017;47(8):1531-1541. doi: 10.1007/s40279017-0682-6. PMID: 28120238..

26. Pin T, Dyke P, Chan M. The effectiveness of passive stretching in children with cerebral palsy. Dev Med Child Neurol. 2006;48(10):855-62.

doi: 10.1017/S0012162206001836. PMID: 16978468.

Disclaimer: None to declare.

Conflict of Interest: None to declare.

Funding Sources: None to declare. 